DOUTRINA.

\title{
A Eqüidade no Direito do Trabalho*.
}

\author{
Miguel Reale \\ Catedrático de Filosofia do Direito da Uni- \\ versidade de São Paulo. Presidente do Ins- \\ tituto Brasileiro de Filosofia.
}

1. Singular tem sido o destino da "equiidade" nos domínios do Direito do Trabalho. Enaltecida por alguns autores como o princípio por excelência do Direito trabalhista, é por muitos objeto de simples notas marginais, enquanto que outros chegam mesmo a apontá-la como um conceito inútil, superado pela certeza das normas, segundo diretrizes objetivas do progresso científico

Não é somente quanto ao valor atribuído à eqüidade que divergem os mestres do Direito do Trabalho, mas também no que se refere à colocação do tema, que ora é visto de maneira genérica, em função do problema da justiça, ora é sumariamente reduzido a simples critério auxiliar de interpretação do Direito vigente. Daí a necessidade de ser reexaminado o assunto, não só à luz de exigências teoréticas, mas também de conformidade com os reclamos da prática, aferidos pelos operadores do Direito do Trabalho nos organismos judiciais, administrativos, sindicais e empresariais.

Declaro desde logo que não me parece assistir razão àqueles que, seduzidos pelas aparentes certezas de uma compreensão naturalista ou fisicalista do Direito, vêm na eqüidade o resquício de uma fase pré-científica da experiência jurídica. Entendo, ao contrário, que, por mais que se aperfeiçoem as técnicas de revelação e de comunicação das regras jurídicas, subsistirá sempre a equiidade como um valor imprescindível, cuja natureza e alcance merecem ser objeto de rigorosa e objetiva análise.

(*) Comunicação ao Congresso. 
2. Antes de procurar fixar alguns pontos que julgo capitais, não será demais recordar que, sob o prisma histórico, e de uma história recente, de cerca de um século, o Direito do Trabalho foi se constituindo e afirmando como um Direito de exceção, isto é, como um complexo de soluções normativas, de ordem legal, consuetudinária, jurisprudencial ou negocial, que o desenvolvimento econômico-industrial veio paulatinamente configurando, destacando-o do sistema do Direito comum.

Nesse sentido, como observou RANELletti, o que ocorreu foi um retorno ao conceito de eqüidade dos romanos, sendo certo que, em diversos países, muitas normas do Direito do Trabalho foram do "criação pretoriana", ou seja, o resultado do poder plasmador do juiz, adequando as regras, por demais abstratas do Direito comum, à concreção própria das relações de trabalho, sobretudo quando veio a prevalecer a consciência ético-social da garantia devida aos mais fracos no desenrolar do fato econômico.

Nesse processo de instauração de um Direito novo, que assinala um dos momentos cruciais do impacto tecnológico sobre as estruturas sociais de nosso tempo, a eqüidade, ainda quando não invocada ou trazida à plena consciência do legislador e do juiz, operava em dois sentidos: como valor ou critério inspirador de adequação da regula juris à especificação dos casos particulares, e como instrumento de instauração de novas normas mais adequadas às situações emergentes do progresso industrial. Atuava, em suma, desde logo, no plano operacional da hermenêutica, e, quase que concomitantemente, na esfera da formulação normativa.

A essa luz, poderemos dizer que a eqüidade banha as matrizes do Direito do Trabalho, não apenas na acepção geral de humanitas e bienignitas, que caracterizaram o Direito Romano justianeu e medieval, mas, também, no sentido de uma exigência de concretude, de adequação necessária ao caso concreto, que nos faz remontar ao conceito aristotélico de eqüidade e ao que prevaleceu no Direito clássico ${ }^{1}$.

1. Cfr. F. M. ROBERTIS - I rapporti di lavoro nel diritto romano, Milão, 1946. Como observa FRANCESCO CALASSO, no Direito Romano Cristão a aequitas representa "um princípio ideal de justiça humana", composta de elementos jurídicos e meta-jurídicos, superior ao jus, enquanto que, no Direito Romano clássico, ela designa "um princípio singularmente jurídico, o fim supremo ou a força ideal que informa todo o sistema do Direito Positivo" (Medio Evo del diritto, Milão, 1954, Vol. I, p. 332). Sobre essa distinção, v. nosso estudo "Concreção de fato, valor e norma 
Deve notar-se que, instaurado segundo um processo inicial de excepcionalidade, sob a inspiração da eqüidade, como ideal ético e como exigência jurídica concreta, o Direito do Trabalho deixou de ser um Direito de exceção ou de classe, para atuar transformadoramente, em contrapartida, sobre o restante da experiência jurídica, alterando a fisionomia do Direito comum, cuja "socialidade" veio cada vez mais se acentuando. Pode-se dizer que a "exigência de concreção", que é uma das feições da problemática da eqüidade, e é hoje reconhecida como uma das notas características do Direito contemporâneo, encontrou, por assim dizer, na esfera do Direito do Trabalho o seu "habitat" natural, dele se irradiando para os demais planos da experiência jurídica.

Não pode, pois, deixar de causar estranhesa que, nascido sob a cálida luz da equiidade, o Direito do Trabalho nem sempre lhe tenha atribuido o papel relevante que lhe cabe.

3. Essa breve remissão histórica auxilia-nos a colocar o problema que nos ocupa, porquanto já nos revela a dupla expressão ou valência do conceito de equiidade na tela do Direito do Trabalho, onde a questão apresenta característicos especiais, encontrando, no dizer de MaRIo De La Cueva, "talvez su campo próprio de acción" 2

Em primeiro lugar, tanto no Direito do Trabalho como nos demais ramos da Jurisprudência, a eqüidade atua como "uma forma peculiar de justiça", tal como, segundo uma consagrada tradição, consta do ensinamento de Aristóteless. Para o Estagirita, a eqüidade e a justiça não são, em sentido absoluto, nem a mesma coisa, nem coisas de gênero diverso: "o equitativo é também justo, não segundo a lei, mas sim como correção e suplemento do justo legal", visto ser "da natureza do equitativo integrar a lei quando esta é insuficiente, em virtude de sua expressão genérica" ${ }^{3}$. Daí a interpretação corrente de que, na doutrina de ARISTóte-

no Direito Romano clássico", em Horizontes do Direito e da Historia, São Paulo, 1956, p. 58 e segts. Cfr., outrossim, para uma síntese da evolução operada no conceito de "aequitas", JOSEF ESSER - Grundsatz und Norm, 2. ${ }^{\mathrm{a}}$ ed., Tubinga, 1964, p. 65 e segts.

2. Cfr. MARIO DE LA CUEVA - Derecho Mexicano del Trabajo, 2. ${ }^{\mathrm{a}}$ ed., México, 1943, p. 337.

3. Cfr. ARISTÓTELES - Ética a Nicômaco, V, 1136a-1138a; e Retórica, I, 1374 a-b-. 
LES:, "a eqüidade é a justiça do caso concreto", enquanto que outros contestam seja esse o pensamento do Filósofo, afirmando que a sua doutrina melhor seria expressa com esta outra fórmula: "a equiidade é o direito do caso concreto" 4

$\mathrm{Na}$ realidade, mais do que uma contraposição, trata-se, no meu entender, de dois pontos de vistas complementares, ambos essenciais à plena compreensão da eqüidade, correspondendo o primeiro ao que ESSER qualifica de sentido "não técnico e jurídico-ético" ("untechnish-rechtsethischen") e o segundo ao que esse autor apresenta como sentido "técnicosistemático" (technisch-systematischen")

Quando dizemos que a eqüidade visa a realizar a justiça "in concreto", pensamos, efetivamente, num complexo de valores ético-sociais, tendo como base o valor da igualdade, a fim de que a rígida aplicação da regra de direito, dada a sua abstração e generalidade, não conduza a uma solução incompatível com os fins mesmos que ela almeja atualizar. Nesse sentido, a eqüidade opera como um critério básico de orientação hermenêutica, atendendo à "natureza das coisas" e, mais especificamente, à particularidade de cada caso. Não há, nesta hipótese, carência de norma, nem se pode falar em lacuna no sistema: o que se dá apenas é uma desconformidade entre a abstração da norma e os característicos do caso particular, impondo-se que aquela se adeque às exigências ético-jurídicas daquilo que é peculiar. Estamos, pois, diante de um princípio norteador do processo interpretativo, de natureza corretiva e adaptadora, para alcançar a "justiça do caso particular"

Hipótese diversa se configura quando há efetivamente lacuna no sistema, e dađa a natureza do caso, impõe-se que a sua integração se faça por eqüidade: a eqüidade, nessa circunstância, dá origem ao "direito do caso particular", preenchendo a lacuna.

4. Na linha de interpretação tradicional, v. EDUARDO GARCIA MAYNEZ, Lógica del raciocinio jurídico, México, 1964, p. 92; e LUfS RECASENS SICHES - Nueva Filosofia de la Interpretación del Derecho, México, 1956 , p. 253 e segts. ("la equidade es. lo autenticamente justo respecto del caso particular"). Opta pela outra interpretação VITORIO FROSINI - "La struttura del giudizio di equità", em Teoremi e problemi di scienza giuridica, Milão, 1971, p. 199 e segts., e também na Enciclopedia del Diritto, t. XV, verbete, "Equità", p. 69 e segts. 
E a esta segunda função da equiidade que mais propriamente se refere FRANCESCo CARNelutti, quando a considera instrumento de "heterointegração" ("eterointegrazione") preenchendo os vazios do ordenamento jurídico 5

Mas, como escreve GaRcia MÁYNez, "importa percatarse de que la necesidad de atender a las peculiaridades de cada negócio no sólo existe quando hay vacios en las fuentes de creación jurídica, sino quando el órgano aplicador encuentra que la especie ha sido legalmente prevista", porém de maneira abstrata, referindo-se a classes de sujeitos e situações, "lo que exige la individualización de los elementos de cada relación concreta" 6

4. Assentes esses critérios e distinções sobre os dois referidos conceitos complementares de eqüidade, já podemos verificar como eles operam no campo do Direito do Trabalho. Este é, por sua natureza, um Direito a que é inerente um "sentido dinâmico", de contínua adequação às estruturas sociais em mudança, sempre visando a garantir aos protagonistas do trabalho a plenitude de seu ser pessoal, numa permanente conciliação entre valores individuais e grupalistas.

Bastaria esta nota de "dinamicidade social", a que se referem tantos autores, ao procurarem caracterizar "o espírito do Direito do Trabalho", para desde logo se ter de reconhecer que o papel desempenhado pela eqüidade nos domínios da Jurisprudência, em geral, se revela ainda mais significativo na tela da Hermenêutica trabalhista, cujas relações implicam sempre um "ser situado num quadro de peculiares circunstâncias", como é o caso do trabalhador ou do empresário.

Natural, por conseguinte, que o operador do Direito do Trabalho, tendo de aplicar a situações concretas uma regra abstrata, pertinente a uma "classe de atos ou de fatos", procure obedecer a critérios equitativos para a atualização da lei, não para contrariá-la, mas antes para realizála em sua plenitude e concreção, segundo a raiz de seu ditame, e não segundo os elementos formais que a ocultam ou a enrijecem.

5. v. F. CARNELUTTI - Sistema di diritto processuale civile, 1936, Vol. I, p. 117 e segts.

6. Op. cit., p. 93 . 
Nessa tarefa, não é mister que o juiz esteja autorizado legalmente a decidir por eqüidade, bastando que, "in casu", não haja lẹi que expressamente o proiba ${ }^{7}$

Exemplo típico da projeção da eqüidade na esfera do Direito Trabalhista é o que se costuma enunciar como "princípio pro operario", que consagra, na dúvida, a solução mais favorável ao trabalhador. A Justiça do Trabalho no Brasil, por exemplo, tem reconhecido "a regra fundamental de interpretação das leis trabalhistas de que, em caso de dúvida, deve ser decidido o assunto em favor do empregado" ${ }^{8}$. Na legislação italiana, bem como em outras, vigora igualmente a presunção legal do trabalhador como contraente mais fraco, o que, no dizer de Gruliano MazZoNI, implica "o princípio do tratamento mais favorável, qualquer que seja a fonte reguladora" 9

Como todo "juizo de eqüidade" se reduz, em última análise, a uma "razão de igualdade", podemos dizer que, no denominado "princípio pro operário" há o propósito de assegurar entre o empregador e o empregado uma relação concreta de paridade. A essa luz, penso eu que o referido princípio deveria perder o seu caráter absoluto, para atender-se à estrutura de cada relação de trabalho, pois nem sempre o princípio "pro operário", que já foi considerado um tanto simplista, atende a um real desequilíbrio entre os sujeitos da relação. Nessa linha de pensamento, tem-se dito que,

7. Na legislação trabalhista seria ainda mais ruinoso o infeliz dispositivo que acaba de ser consagrado pelo art. 127 do novo Código de Processo Civil Brasileiro, que assim reza: "O juiz só decidirá por equiidade nos casos previstos em lei" Nada mais contrário à eticidade essencial do Direito do que esse pseudo conceito de eqüidade autorizada"

8. Cfr. CESARINO JUNIOR - Consolidação das Leis do Trabalho, 4.a ed., São Paulo, 1956, Vol. I, p. 101. Sobre a equiidade no Direito do Trabalho, no Brasil, v. MIGUEL MARIA E. SERPA - "A equiidade e a função do intérprete", na "Revista do Trabalho e Seguro Social", 1943, p. 109 e segts.; A. B. COTRIM NETO - "Conceito de equiidade no Direito do Trabalho", em "Revista do Trabalho", 1941, n.o 8, p. 17 e segts.; OLIVEIRA VIANA - Problemas de Direito Sindical, Rio, 1943; EVARISTO DE MORAES FILHO - Introdução ao Direito do Trabatho, Rio, 1956, Vol. II, p. 489 e segts. e DELLIO MARANHÃO, Direito do Trabalho, 2.a ed., 1971, p. 23 e segts.

9. Cfr. "Enciclopedia del Diritto", Vol. XII, p. 1074. Para uma crítica ao "princípio pro-operário", v. SALVATORE HERNANDEZ, "Il favor del lavoratore come tutela compensativa", em Studi in onore di Francesco Santori-Passarelli, Nápoles, 1972, p. 575 e segts. 
na dúvida, deve prevalecer a solução favorável ao trabalhador, não por ser este sempre o mais fraco, mas sim quando as circunstâncias que cercaram a formação do contrato de trabalho permitem e exigem que este seja equiparado a um "contrato de adesão", resolvendo-se as dúvidas sobre as cláusulas contratuais em benefício do aderente.

O certo é que, de uma forma ou de outra, o Direito do Trabalho é animado pelo sentido de "ajuste" a situações humanas concretas, atuando a eqüidade como critério construtivo de interpretação ${ }^{10}$.

Saliente-se, porém, que, nessa diretriz, não há que se falar em equiidade contra legem, como pretenderam sustentar alguns mentores de uma aequitas cerebrina, cuja consequência seria comprometer o valor da certeza jurídica, tão essencial ao Direito do Trabalho como aos demais campos da Jurisprudência. Não é indispensável, todavia, exigir-se que o juiz esteja expressamente autorizado, por lei, para decidir por eqüidade. Esta autorização deve ser considerada implícita, toda vez que a "regula juris", por sua amplitude e abstração, se abrir num leque de aplicações diversas, sendo necessário que prevaleça a mais aderente às peculiaridades do caso particular. Como pondera LUIGI BAGolinI, em admirável estudo, a fidelidade que o juiz deve à lei "não pode ser o resultado de pura descrição analítica ou empírica de eventos pensados em uma sucessão temporal objetivada no espaço", mas implica que, ao ser apreciado um caso em sua singularidade, seja ele situado também à luz dos valores todos implícitos no cosmo jurídico ${ }^{11}$.

Por outro lado, talvez se possa dizer que não é estranha à idéia de equidade e de juizos equitativos a persistente preferência que, no desempenho da Justiça trabalhista, muitas vezes é dada a magistrados extraídos das categorias profissionais, para atuarem ao lado dos juizes de carreira, possibilitando um conhecimento mais vivo e direto das relações de trabalho e de suas peculiares circunstâncias.

10. Com razão adverte GERARD LYON CAEN que o Direito do Trabalho, "por seu conteúdo humano, obriga o jurista a ir além das discussões formais e a ver, por detrás dos argumentos jurídicos, a luta dos homens" (Manuel du Droit du Travail, Paris, 1955, p. 33).

11. Cfr. L. BAGOLINI - "Fedeltà al diritto e interpretazione", in "Annali della Facoltà di Giurisprudenza" da Universidade de Gênova, Ano XII, 1973 , fasc. 2 , p. 300 e segts. 
5. Ao lado desse emprego da eqüidade como critério de interpretação das regras jurídicas, situa-se, como já salientei, a sua função como instrumento de integração do ordenamento, em ocorrendo lacuna no sistema das normas legais ou costumeiras.

Geralmente, as legislações dispõem que, verificada a existência de lacuna no sistema legal, deve o intérprete recorrer à analogia, ao costume e aos princípios gerais de direito. Ora, entre os processos de "heterointegração" figura a eqüidade, como decorrência do princípio geral de direito segundo o qual devem ser tratados igualmente os iguais, e desigualmente os desiguais, na medida em que se desigualem, o que é um imperativo de justiça "in concreto" Daí admitirem vários tratadistas do Direito do Trabalho, como o faz Giuliano Mazzoni, que, nos casos omissos, pode haver "recurso à equiidade, atribuindo-se ao juiz a faculdade de integrar ou de criar a norma para o caso concreto" 12 .

Não se deve, porém, concluir que a eqüidade seja "fonte do direito", como ainda se continua a repetir, dando-se a ambos os termos uma acepção genérica imprecisa. Na realidade, o que se dá, na hipótese de preenchimento de lacuna, é o emprego da eqüidade para elaborar-se o "modelo normativo" adequado ao caso particular, o que, repito, só é admissível "praeter legem", e jamais "contra legem" Cabe sobretudo à doutrina oferecer os elementos necessários à formação de um juizo de equiidade, o que culmina na configuração de um "modelo dogmático", que, consagrado pelos órgãos jurisdicionais, se converte em "modelo jurídico", para empregar aqui uma distinção estabelecida em meu livro "O Direito como Experiência", propondo seja a "teoria das fontes" retificada e completada por uma "teoria dos modelos jurídicos" 13

A meu ver, só se pode falar em "fonte de direito", na acepção rigorosa deste termo, quando há uma "estrutura de poder", em função da qual uma determinada "solução normativa" se torna objetivamente obrigatória como diretriz jurídica válida. Toda "fonte" ou "forma" de revelação de direito pressupõe uma "estrutura de poder", originário ou de-

12. v. G. MAZZONI - Manuale di Diritto del Lavoro, 3.a ed., 1969, p. 267.

13. Cfr. MigUEL REALE, op. cit., São Paulo, 1963, capítulos VII e VIII. (Há trad. italiana por mim revista e ampliada, com Introdução de DOMENICO COCCOPALMERIO. - Il diritto come esperienza, Ed. Giuffré, 1973). 
rivado, seja ele o "poder legal", que dá origem aos "modelos legais"; o "poder social" que dá nascimento aos "modelos costumeiros"; o "poder judicial", que instaura os "modelos jurisprudenciais"; ou, "last, not least", o "poder ou autonomia da vontade" que dá origem aos "modelos negociais".

A doutrina, propriamente dita, não é fonte de direito, nem gera modelos jurídicos. Seu papel é bem outro, mas não menos relevante e decisivo: é ela que nos permite saber o que significam os modelos jurídicos, traçando, além disso, os limites de sua legitimidade e alcance. Dela resultam os "modelos dogmáticos", ou teóricos, cuja função é determinar a significação dos "modelos jurídicos", significação essa que não é estática, mas variável, desde quando são aqueles emanados até a sua perda de validade. Pois bem, dentro dessa concepção, a eqüidade não pode e não deve ser vista como fonte do direito, mas sim como critério de exegese ou elemento de integração normativa. Em ambos os casos, a doutrina configura juizos de eqüidade que completam o ordenamento jurídico, ou the suprem as lacunas, convertendo-se eles em "modelos legais" ou "modelos jurisprudenciais" quando o Poder Legislativo ou o Judiciário consagram, respectivamente, os seus ditames. 